\title{
Impact of Sedimentation of Cloud Ice on Cloud-Top Height and Precipitation Intensity of Precipitation Systems Simulated by a Cloud-Resolving Model
}

\author{
Mitsuharu NOMURA \\ Hydrospheric Atmospheric Research Center, Nagoya University, Nagoya, Japan \\ Kazuhisa TSUBOKI \\ Hydrospheric Atmospheric Research Center, Nagoya University, Nagoya, Japan \\ Frontier Research Center for Global Change, Yokohama, Japan \\ and \\ Taro SHINODA \\ Hydrospheric Atmospheric Research Center, Nagoya University, Nagoya, Japan \\ (Manuscript received 30 September 2011, in final form 20 June 2012)
}

\begin{abstract}
This study uses a cloud-resolving model to examine the impact of sedimentation of cloud ice on the cloud-top height and the precipitation intensity of typical precipitation systems in East Asia, including a typhoon, snow clouds over the Sea of Japan, and the Baiu front. The fall velocity of cloud ice is assumed to be $0.1 \mathrm{~m} \mathrm{~s}^{-1}$. When the sedimentation process of cloud ice is included in the model, the horizontal distribution and frequency of the cloud-top height show significantly better agreement with satellite observations. Furthermore, cloud ice with sedimentation concentrates at a lower level than that without sedimentation, and converts to snow and graupel by microphysical growth processes. More solid water substances located in the thin layer above the $0^{\circ} \mathrm{C}$ level contribute to intensification of precipitation at the surface by several percent, especially in the convective area.
\end{abstract}

\section{Introduction}

Bulk cold rain parameterization is widely used in many cloud-resolving models (CRMs) for representing clouds and precipitation. It is comprised of two categories of water substances. The first includes precipitation particles, such as rain water, snow, and graupel/hail. The other includes cloud particles, such as cloud water and cloud ice.

Corresponding author and present affiliation: Mitsuharu Nomura : Central Research Institute of Electric Power Industry, 1646 Abiko, Abiko-Shi, Chiba 270-1194, Japan E-mail: nomuharu@criepi.denken.or.jp

(C)2012, Meteorological Society of Japan
The fall velocity of water substances is one of the important factors in the precipitation process. The fall velocity of cloud particles was set to zero in the model of Lin et al. (1983) because the size of cloud particles was sufficiently small to ignore the sedimentation compared to the size of the precipitation particles. When the fall velocity is ignored, the model accumulates excessive cloud ice in the upper troposphere. As a result, the cloud radiation calculation is expected to be inaccurate. Besides sedimentation, only the sublimation process reduces the amount of cloud ice in the upper troposphere. However, this process is ineffective under usual conditions because the upper troposphere is easily saturated with ice with a small amount of 
water vapor.

To recognize the sedimentation of cloud ice, the particle size distribution (PSD) of cloud ice is important for calculating the average terminal velocity. Previous studies have observed the PSD of cloud ice using aircraft (e.g., Heymsfield et al. 2004; Heymsfield et al. 2007a), the hydrometeor videosonde (HYVIS: Murakami and Matsuo 1990), and other means. Heymsfield et al. (2007a and 2007b) investigated cloud ice particle mass dimension and terminal velocity relationships. They determined the coefficients for the mass dimensional and fall velocity relationships as well as the mean effective density for the ice particle population. Heymsfield et al. (2007b) also showed that the fall velocity of small ice particles with an average diameter $<0.1 \mathrm{~mm}$ was approximately $0.5 \mathrm{~m} \mathrm{~s}^{-1}$. Murakami et al. (1994b) examined the distribution of cloud ice and supercooled cloud droplets including the microphysical structure of convective snow clouds over the Sea of Japan using the HYVIS, the hydrometer video dropsondes (HYDROS), multiple Doppler radars, and a microwave radiometer. However, they did not show the relationship between the PSD and the fall velocity of cloud ice.

In the microphysical parameterization, the fall velocity of water substances has been formulated using observed and experimental data. The equation of the fall velocity in most microphysical parameterizations is

$$
U_{x}\left(D_{x}\right)=\alpha_{x} D_{x}^{\beta_{x}}
$$

where $\alpha_{x}$ and $\beta_{x}$ are the constants in the empirical formula for $U_{x}\left(D_{x}\right) . D_{x}$ is the diameter of the water substance, and $x$ is the water substance categories. For the calculation of $D_{x}$, Murakami (1990) and Ikawa and Saito (1991) assumed that the PSD of cloud ice was monodisperse. In recent CRM development, Ferrier (1994), Milbrandt and Yau (2005), and Straka and Mansell (2005) introduced the fall velocity of cloud ice using the assumption of the Marshall-Palmer or gamma distributions. However, the effect of the fall velocity of cloud ice was not sufficiently discussed in these studies. In particular, little attention has been given to the impact of the sedimentation of cloud ice on the precipitation intensity within various precipitation phenomena.

Hong et al. (2004) studied the impact of cloud ice sedimentation by performing numerical experiments in an ideal and a real heavy rainfall case. They showed that the impact of cloud ice sedimentation was large on the ice cloud-radiation feedback and the precipitation amount in the long-term experiment. Heymsfield et al. (2007b) introduced the PSD function, the ice water content shown in Heymsfield et al. (2007a), and the radar reflectivity to the model of Lin et al. (1983). They reported an improvement in the fall velocity estimate by introducing their parameters and functions. However, these studies did not discuss in detail the impact of the sedimentation of cloud ice on the precipitation intensity and processes within various precipitation phenomena.

In the present study, we introduce the sedimentation process of cloud ice into a CRM known as the Cloud Resolving Storm Simulator (CReSS: Tsuboki and Sakakibara 2002), which was previously applied to reproduce precipitation system structures (Liu et al. 2004; Wang et al. 2005; Yamada et al. 2007; Shimizu et al. 2008). In these studies, the CReSS results showed good qualitative agreement with the observed results. However, the quantitative validation of the simulation results was inadequate. Therefore, this study introduces a proper parameterization of the sedimentation process of cloud ice, and examines the impact of this process on typical precipitation systems in East Asia, including a typhoon, snow clouds over the Sea of Japan, and the Baiu front. To explain the impact of the sedimentation of cloud ice on cloud-top height and precipitation intensity, we simplify the complicated formulation of the fall velocity of cloud ice and assume a constant fall velocity

\section{Model and experimental design}

\subsection{Model description}

The numerical model used in the present study is CReSS. This is formulated on the basis of the nonhydrostatic and compressible equation systems with terrain-following coordinates. No convective parameterization is included. A 1.5-order turbulent kinetic energy (TKE) closure scheme is applied for subgridscale parameterization. The prognostic variables include 3-D velocity components, perturbations of pressure and potential temperature, subgrid-scale TKE, mixing ratios of water vapor $\left(q_{v}\right)$, cloud water $\left(q_{c}\right)$, rain water $\left(q_{r}\right)$, cloud ice $\left(q_{i}\right)$, snow $\left(q_{s}\right)$, and graupel $\left(q_{g}\right)$, and number concentrations of solid water substances including cloud ice, snow, and graupel. Mixing ratio of precipitation $\left(q_{p}\right)$ is the sum of $q_{r}, q_{s}$, and $q_{g}$.

The cloud microphysical processes in CReSS are a bulk cold rain parameterization based on Murakami (1990) and Murakami et al. (1994a) with additions and modifications of the processes. The cloud microphysical processes in this model are illustrated in Fig. 1. The prognostic equations for the mixing ratio of the water substances are 


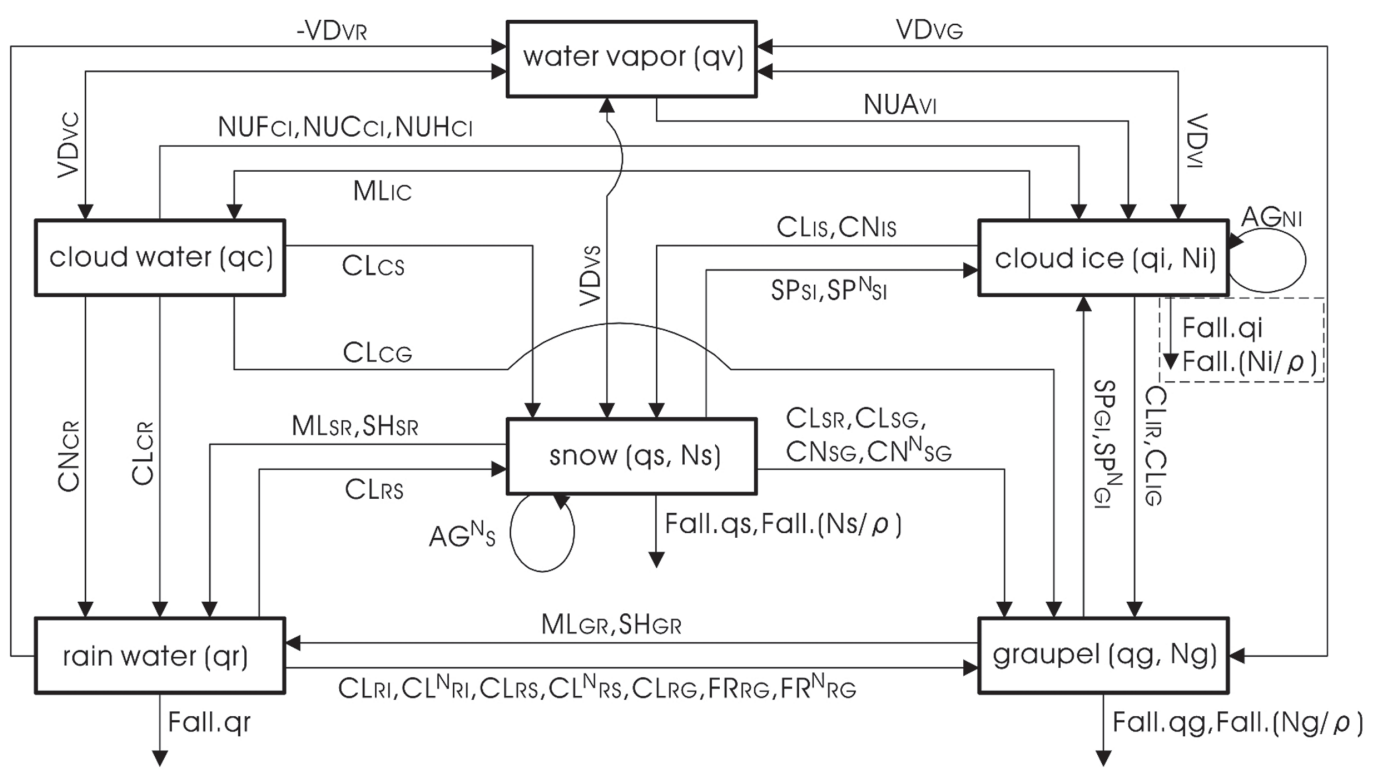

Fig. 1. Cloud microphysical processes included in CReSS. Term notation is described in the appendix. Sedimentation process of cloud ice. Fall.qi and Fall.(Ni/ $\rho)$, are introduced in the FL case.

$$
\begin{aligned}
& \frac{\partial \bar{\rho} q_{v}}{\partial t}=A d v \cdot q_{v}+\text { Tub. } q_{v}+\bar{\rho} S r c \cdot q_{v} \\
& \frac{\partial \bar{\rho} q_{x}}{\partial t}=A d v \cdot q_{x}+\text { Tub. } q_{x}+\bar{\rho} S r c \cdot q_{x}+\bar{\rho} \text { Fall. } q_{x}
\end{aligned}
$$

where $x$ in (3) is the water substance category, including cloud water (c), rain water (r), cloud ice (i), snow (s), and graupel (g). $\rho$ represents air density. Furthermore, Adv. $q_{x}$, Tub. $q_{x}$, Src. $q_{x}$, are the advection, turbulent diffusion, and source terms of the water substances, respectively. Fall. $q_{x}$ is the fall-out term of precipitation. The source terms of the water substances are formulated as follows

$$
\begin{aligned}
\text { Src. } q_{v}= & -N U A_{V I}-V D_{V R}-V D_{V I}-V D_{V S}-V D_{V G} \\
\text { Src. } q_{c}= & -N U F_{C I}-N U C_{C I}-N U H_{C I}-C L_{C R} \\
& -C L_{C S}-C L_{C G}-C N_{C R}+M L_{I C} \\
\text { Src. } q_{r}= & V D_{V R}+C L_{C R}-C L_{R I}-C L_{R S}-C L_{R G} \\
& +C N_{C R}+M L_{S R}+M L_{G R}-F R_{R G} \\
\text { Src. } q_{i}= & N U A_{V I}+N U F_{C I}+N U C_{C I}+N U H_{C I} \\
& +V D_{V I}-C L_{I R}-C L_{I S}-C L_{I G} \\
\text { Src. } q_{S}= & -S P_{S I}+V D_{V S}+C L_{C S}+C L_{R S} \alpha_{R S} \\
& +C L_{I S}-C L_{S R}\left(1-\alpha_{R S}\right)-C L_{S G}
\end{aligned}
$$

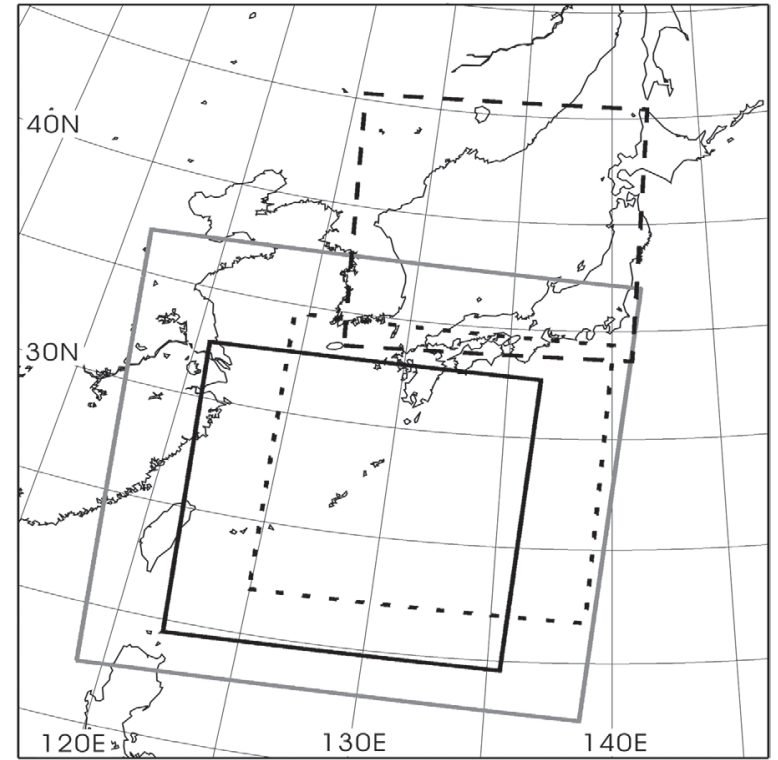

Fig. 2. Experimental domains of $\mathrm{T}-5 \mathrm{~km}$ (gray solid rectangle), $\mathrm{T}$ case (black solid rectangle), $\mathrm{B}$ case (dotted rectangle), and $\mathrm{S}$ case (dashed rectangle). 
Table 1. Numerical experiment design of T, S, and B cases.

\begin{tabular}{cccc}
\hline case & T case & S case & B case \\
\hline grid numbers & $743 \times 743 \times 48$ & $651 \times 661 \times 30$ & $723 \times 703 \times 43$ \\
top height & $24 \mathrm{~km}$ & $14 \mathrm{~km}$ & $21.5 \mathrm{~km}$ \\
initial data & T-5 km & JMA-GSM & JMA-GSM \\
initial time & $03 Z 4$ Sep. 2002 & 12 Z 31 Dec. 2007 & $18 Z$ 11 Jun. 2008 \\
integrated time & 21 hours & 15 hours & 24 hours \\
\hline
\end{tabular}

$$
\begin{aligned}
\text { Src. } q_{g}= & -S P_{G I}+V D_{V G}+P G_{G}+C L_{R I}+C L_{I R} \\
& +\left(C L_{R S}+C L_{S R}\right)\left(1-\alpha_{R S}\right)
\end{aligned}
$$

where the detailed cloud microphysical term notation is described in the appendix. Here, $\alpha_{R S}$ represents the production of graupel due to collisions between raindrops and snow. For the evaporation or deposition between water vapor and cloud water $\left(V D_{V C}\right)$ in Fig. 1, the moist saturation adjustment method of Soong and Ogura (1973) is adopted. $S P_{S I}$ and $S P_{G I}$ in terms (7), (8), and (9) are the added processes in CReSS.

The fall velocity of cloud ice in the present study is assumed to be constant at $0.1 \mathrm{~m} \mathrm{~s}^{-1}$ defined by the formula shown in Murakami et al. (1994a) with an average ice particles diameter of $0.1 \mathrm{~mm}$. This is equivalent to the fall velocity of cloud ice in the Japan Meteorological Agency (JMA) Meso-Scale Model (MSM) without the parameter adjustment (Hayashi et al. 2008). To simply understand the impact of the cloud ice sedimentation on the precipitation system, we introduce the constant fall velocity of cloud ice without the improvement in parameters in the formula.

\subsection{Experimental design}

We performed numerical experiments with a horizontal resolution of $2 \mathrm{~km}$ for three cases: Typhoon SINLAKU (T0216: T), snow clouds over the Sea of Japan (S), and the Baiu front (B). Sensitivity experiments with (FL) and without (NF) the cloud ice sedimentation process were performed for each case. In the following section, the sensitivity experiment nomenclature reflects the case and the sensitivity (e.g., T-FL and $\mathrm{T}-\mathrm{NF}$ for $\mathrm{T}$ case).

The experimental domains of the three cases are shown in Fig. 2. To set the initial data for $\mathrm{T}$ case, we conducted a numerical simulation with a horizontal resolution of $5 \mathrm{~km}(\mathrm{~T}-5 \mathrm{~km})$ for 24 hours using the output of the Regional Spectrum Model (RSM) with a horizontal grid spacing of $20 \mathrm{~km}$ provided by JMA. The initial time of JMA-RSM was 00Z 4 September 2002. The simulation domain of $\mathrm{T}-5 \mathrm{~km}$ is also shown in Fig. 2. We used the data of the Global Spectral Model (GSM) with a horizontal resolution of $20 \mathrm{~km}$ provided by JMA as the initial and boundary conditions for $\mathrm{S}$ and $\mathrm{B}$ case. The vertical resolution is stretched from $100 \mathrm{~m}$ in $\mathrm{T}$ case and $150 \mathrm{~m}$ in $\mathrm{S}$ and $\mathrm{B}$ cases at the lowest level to $500 \mathrm{~m}$ at the top level. An additional configuration of these simulations is shown in Table. 1.

To analyze of the precipitation amount, the precipitation area was separated into convective and stratiform areas by the method developed in Steiner et al. (1995) using horizontal distributions of radar reflectivity and the sharpness of the reflectivity peaks. In this study, the horizontal distributions of the radar reflectivity were calculated with the precipitation mixing ratio $\left(q_{r}\right.$, $q_{s}$, and $q_{g}$ ) at a height of $2 \mathrm{~km}$ in $\mathrm{T}$ and B cases and 1 $\mathrm{km}$ in $\mathrm{S}$ case using the conversion method shown in Murakami (1990). In addition, Steiner's separation was applied to these data. The analysis was restricted to a radius of $300 \mathrm{~km}$ from the typhoon center in $\mathrm{T}$ case, over the Sea of Japan in S case, and to $150 \mathrm{~km}$ on both sides of the Baiu front in B case.

\section{Impact of sedimentation of cloud ice}

\subsection{Distribution of cloud and precipitation}

a. T case

We examine the impact of sedimentation of cloud ice in T case at 20 hours. The difference between FL and NF is most notable at that time. Figure 3 shows the horizontal distribution of the brightness temperature $\left(T_{b b}\right)$ in the infrared band (IR-1: $\left.10.8 \mu \mathrm{m}\right)$ and the rainfall intensity. $T_{b b}$ corresponds to the cloud-top height. The observational distributions of $T_{b b}$ and rainfall intensity were obtained by the Geostationary Meteorological Satellite (GMS) and the JMA radar at $23 \mathrm{Z}$ 4 September 2002. The simulated distribution of $T_{b b}$ was calculated using the Satellite Data Simulator Unit (SDSU: Masunaga et al. 2010). The cloud-top height of T-FL is clearly lower than that of T-NF.

The cumulative probability densities of $T_{b b}$ obtained by the GMS observation, T-FL, and T-NF within the analysis area are shown in Fig. 4. The frequencies of the upper clouds, where $T_{b b}$ is less than $-60^{\circ} \mathrm{C}$, in 


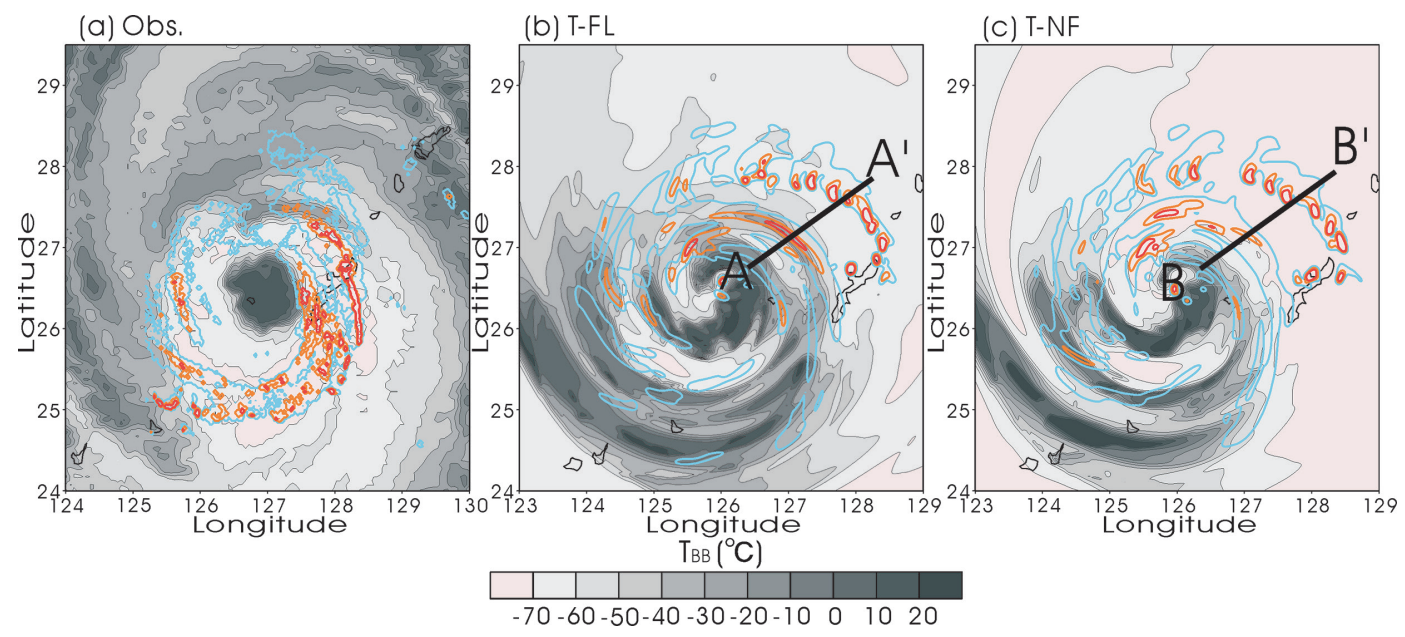

Fig. 3. (a) Horizontal distribution of $T_{b b}$ from the GMS observation and the rainfall intensity from the JMA radar at 23Z. The SDSU $T_{b b}$ image and the rainfall intensity were simulated by CReSS for (b) T-FL and (c) T-NF at 20 hours (23Z). Shadings are $T_{b}$. Contours are rainfall intensities at 4 (blue), 16 (orange), and 32 (red) $\mathrm{mm} \mathrm{h}^{-1}$.

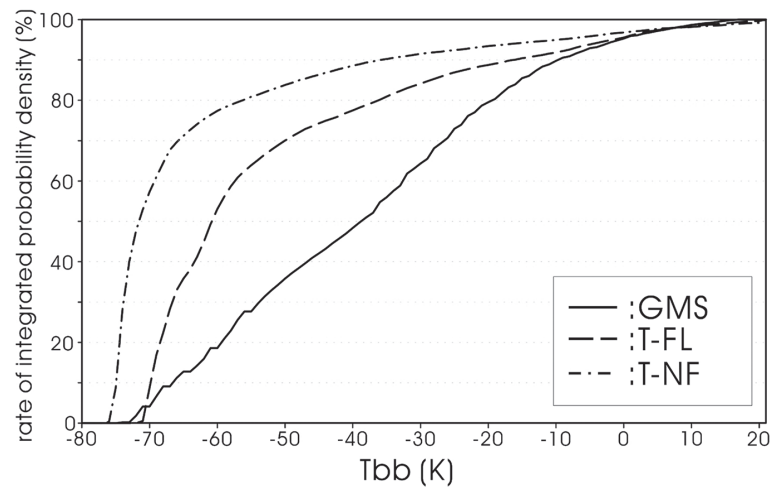

Fig. 4. Cumulative probability densities of the $T_{b b}$ from the GMS (solid line), T-FL (dashed line), and $\mathrm{T}-\mathrm{NF}$ (chain line) within a radius of $300 \mathrm{~km}$ from the typhoon center at $23 \mathrm{Z}$.

both T-FL and T-NF are larger than that of the GMS data. The frequencies of the cloud-top below $-70^{\circ} \mathrm{C}$ are $58 \%$ in $\mathrm{T}-\mathrm{NF}$ and $10 \%$ in $\mathrm{T}-\mathrm{FL}$. The reproduced distribution of the cloud-top height in T-FL is in better agreement with that observed by GMS-IR than that in T-NF. Thus, the introduction of sedimentation of cloud ice has led to an improvement in the estimated cloudtop height.

Several spiral bands defined rainfall intensity larger than $4 \mathrm{~mm} \mathrm{~h}^{-1}$ and several tens of kilometers in length are well simulated in both T-FL and T-NF at 20 hours (Fig. 3). The observational data shows strong rainfall regions with rainfall intensity larger than $16 \mathrm{~mm} \mathrm{~h}^{-1}$ in the region south of the typhoon center. In both simulations, however, these regions were located in the region north of the typhoon center. Although the simulated location of the spiral bands with strong rainfall differs from that of the observation, their vertical structures were analyzed. Figure 5 shows the vertical cross-sections of $q_{c}, q_{i}$, and $q_{p}$ crossing the typhoon center and the strongest precipitation point at the surface. Spiral bands defined by areas with $q_{p}$ larger than $0.5 \mathrm{~g} \mathrm{~kg}^{-1}$ and $10-20 \mathrm{~km}$ in width are simulated at horizontal distances of 120 and $200 \mathrm{~km}$ from the typhoon center in both T-FL and T-NF. The characteristic structures of simulated spiral bands, such as the band-width and the distribution of precipitation above the height of $0^{\circ} \mathrm{C}$, are in accordance with previous studies (e.g., Black and Hallett 1986; Powell 1990). $q_{p}$ in the spiral band of T-FL is larger than that of T-NF. The difference in $q_{p}$ was particularly noticeable above the $0^{\circ} \mathrm{C}$ level. The top of $q_{i}$, which is larger than $0.05 \mathrm{~g} \mathrm{~kg}^{-1}$, is present at an approximate height of $15 \mathrm{~km}$ in T-FL. In contrast, that in $\mathrm{T}-\mathrm{NF}$ reaches a height of $17 \mathrm{~km}$, which is the bottom of the sponge layer. The maximum values of $q_{i}$ in T-FL and T-NF are located at heights of approximately 11.5 and $13 \mathrm{~km}$, respectively. Thus, $q_{i}$ in $\mathrm{T}-\mathrm{FL}$ is $1.5 \mathrm{~km}$ lower than that in T-NF. These results indicate that the sedimentation of cloud ice contributes to lower in the cloud-top height.

\section{b. B case}

Figure 6 shows the horizontal distribution of $T_{b b}$ 

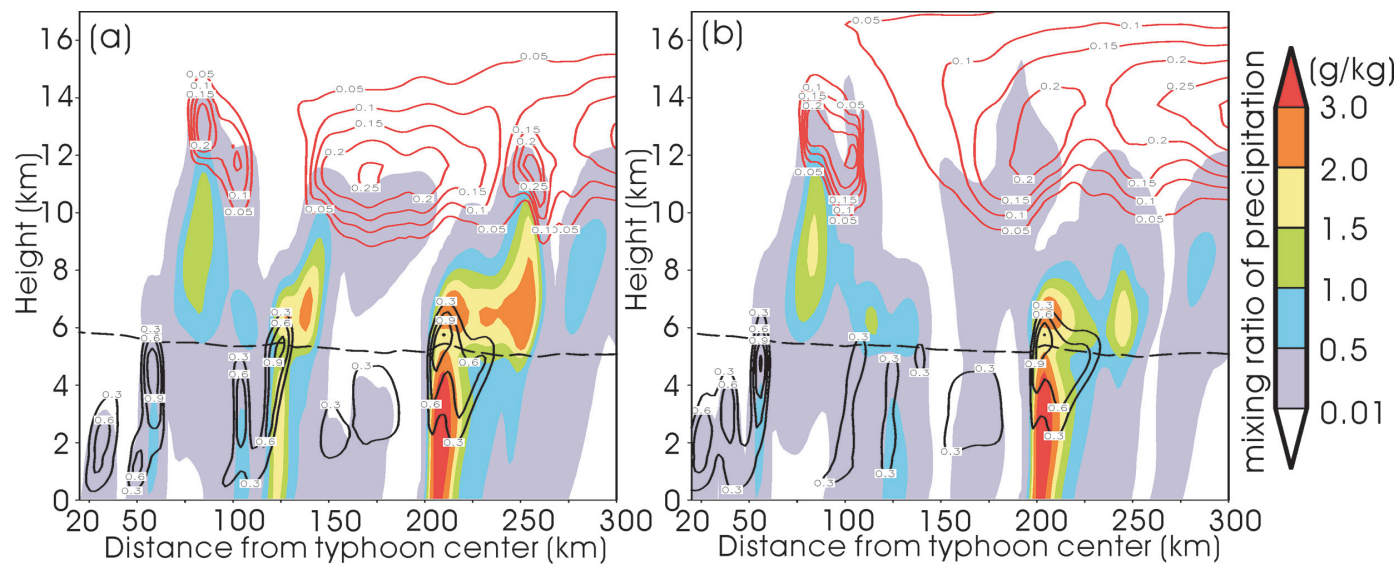

Fig. 5. Vertical cross-sections of water substances along (a) A-A' in Fig. 3b and (b) B-B' in Fig. 3c. Colors are $q_{p}$. Black contours are $q_{c}$ every $0.3 \mathrm{~g} \mathrm{~kg}^{-1}$. Red contours are $q_{i}$ every $0.05 \mathrm{~g} \mathrm{~kg}^{-1}$. Dashed line indicates the $0^{\circ} \mathrm{C}$ level.

(a) Obs.

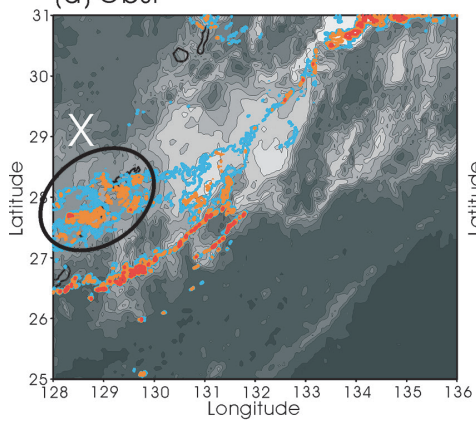

(b) B-FL

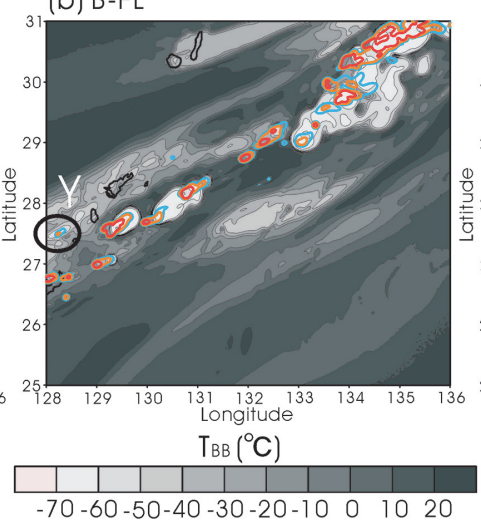

$-70-60-50-40-30-20-10 \quad 0 \quad 1020$ (c) B-NF

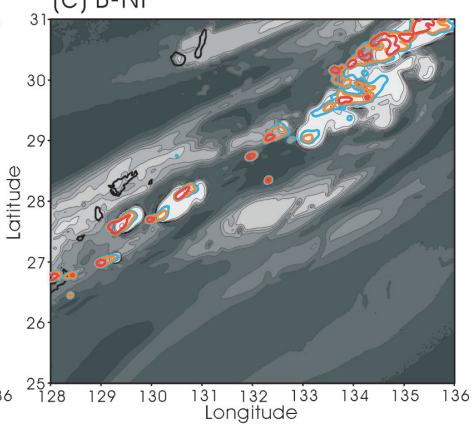

Fig. 6. Same as in Fig. 3, but for (a) MTSAT and JMA radar at 01Z 12 June, (b) B-FL at 9 hours (03Z 12), and (c) B-NF at 9 hours $\left(03 Z 12\right.$ ). Contours are rainfall intensity at 1 (blue), 4 (orange), and 16 (red) $\mathrm{mm} \mathrm{h}^{-1}$.

and rainfall intensity at 9 hours (03Z 12 June) when the precipitation intensities averaged in the analysis domains obtained the maximum precipitation intensity in B-FL case. Data from the Multi-functional Transport Satellite (MTSAT) and the JMA radar data at $01 \mathrm{Z}$ were used because the observed Baiu front was located in the same place as B-FL and B-NF at 9 hours. The characteristic structure of the Baiu front, such as the south-north gradient of $q_{v}$ and the potential temperature in the low level and the low level jet (Matsumoto et. al. 1971), were represented in B-FL and B-NF (not shown). The peak of the cloud-top height in both simulations is higher than in the observation. Comparing the cloud-top height in B-FL with that in B-NF, the area below $-40^{\circ} \mathrm{C}$ above the rainfall region northwest of the central area in B-FL is smaller than that in $\mathrm{B}-\mathrm{NF}$ (Figs. 6b, c).

The distribution of strong rainfall (more than $16 \mathrm{~mm}$ $\mathrm{s}^{-1}$ ) in B-FL and B-NF is similar to that in the observation. The rainfall region north of the strong rainfall region ( $\mathrm{X}$ in Fig. 6a) is not represented in either of the simulations. In the northeast quadrant, the area of the strong rainfall in B-FL is greater than that in B-NF. In other regions, the difference in the rainfall distribution between B-FL and B-NF is small.

The cumulative probability densities of $T_{b b}$ obtained from the MTSAT observation, B-FL, and B-NF within the analysis area are shown in Fig. 7. The frequencies of the upper clouds, where $T_{b b}$ is less than $-60^{\circ} \mathrm{C}$, are $3.2 \%$ in $\mathrm{B}-\mathrm{NF}$ and $1.9 \%$ in $\mathrm{B}-\mathrm{FL}$, although that of the 


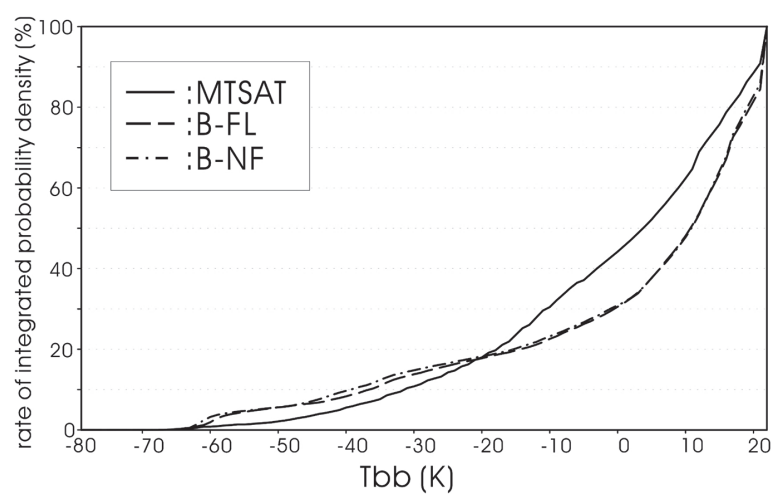

Fig. 7. Same as in Fig. 4, but for MTSAT (solid line), B-FL (dashed line), and B-NF (chain line).

MTSAT data is hardly discernible. The frequencies of the upper clouds within the Baiu frontal zone, where $T_{b b}$ is less than $-30^{\circ} \mathrm{C}$, reduce to approximately $3 \%$ by introducing the cloud ice sedimentation. The simulated distribution of the cloud-top height in B-FL shows slightly better agreement with the MTSAT-IR observation than the distribution of B-NF.

\section{c. Scase}

The characteristic snow clouds over the Sea of Japan, such as the Japan Sea Polar air mass Convergence Zone (JPCZ) defined by Asai (1988) and the longitudinal mode (L- mode) bands, are represented both in S-FL and S-NF at 10 hours (22Z 31 December) when the maximum precipitation intensity was obtained in S-FL case (Fig. 8). The L-mode snow clouds over the mid and southern parts of the Sea of Japan are reproduced; however, those over its northern part are insufficiently simulated. $T_{b b}$ of the L-mode clouds is approximately $-20^{\circ} \mathrm{C}$ in S-FL and S-NF. The cloudtop height over the JPCZ is approximately $-33^{\circ} \mathrm{C}$ in both experiments. These results are in accordance with the MTSAT-IR observation. In S-NF, the cloud-top height below $-40^{\circ} \mathrm{C}$ is present near the Sea of Japan coastline of northern Japan (Fig. 8c). In contrast, the cloud-top height below $-40^{\circ} \mathrm{C}$ does not appear in the observation and S-FL.

The area of rainfall region in both experiments is narrow compared with that of the observation. In particular, the distribution of rainfall in the experiments is narrow over land. The rainfall amount at Tsuruga (open circle in Fig. 8), which is located under the JPCZ, is 4.0 $\mathrm{mm} \mathrm{h}^{-1}$ in the observation, $3.7 \mathrm{~mm} \mathrm{~h}^{-1}$ in S-FL, and $3.6 \mathrm{~mm} \mathrm{~h}^{-1}$ in S-NF at 10 hours. The rainfall amount at Takada (open square in Fig. 8), which is located under the $\mathrm{L}$-mode cloud, is $3.0 \mathrm{~mm} \mathrm{~h}^{-1}$ in the observation, $3.5 \mathrm{~mm} \mathrm{~h}^{-1}$ in S-FL, and $3.5 \mathrm{~mm} \mathrm{~h}^{-1}$ in S-NF at 10 hours. Thus, the rainfall amount under the JPCZ and $\mathrm{L}-$ mode cloud is well represented in S-FL and S-NF.

Figure 9 shows the cumulative probability densities of $T_{b b}$ obtained by the MTSAT observation, S-FL, and S-NF over the Sea of Japan at 10 hours. The frequencies of the deep convective clouds, where is $T_{b b}$ is less than $-22^{\circ} \mathrm{C}$, are $7.7 \%$ in $\mathrm{S}-\mathrm{FL}$ and $11.1 \%$ in $\mathrm{S}-\mathrm{NF}$. The S-FL estimate is in good agreement with the observation. On the other hand, the frequencies of the shallow convective clouds, where $T_{b b}$ is higher than $-20^{\circ} \mathrm{C}$, in S-FL and S-NF are smaller than that in the observation. The cloud top temperatures of the shallow convective clouds over the Sea of Japan are mainly $-20^{\circ} \mathrm{C} \pm$ $3^{\circ} \mathrm{C}$ (Murakami et al. 1994b). This result supports the improvement in the cloud-top height due to the introduction of cloud ice sedimentation.

\subsection{Precipitation amount and intensity}

Table 2 shows the accumulated precipitation amount in the convective and stratiform precipitation areas averaged in the analysis domains for each sensitivity experiment. The sedimentation of cloud ice impacts the accumulated precipitation amount in $\mathrm{T}$ and $\mathrm{B}$ cases. In the convective area (referred as "con." in Table.2), the accumulated precipitation amount from 5 to 21 hours in T-FL is larger than that in T-NF. In B case, the accumulated precipitation amount in $\mathrm{B}-\mathrm{FL}$ is larger than that in B-NF. In the stratiform area (referred as "str." in Table.2), the accumulated precipitation amount from 5 to 15 hours in T-FL and B-FL is larger than that in $\mathrm{T}-\mathrm{NF}$ and B-NF, respectively. In $\mathrm{S}$ case, the difference between the accumulated precipitation amount of S-FL and S-NF in the convective area is very small, while that in S-FL in the stratiform area is smaller than that in S-NF. The precipitation systems of Baiu front and snow clouds decayed after 15 hours in B case and 10 hours in $\mathrm{S}$ case. The accumulated precipitation amount in the stratiform area in the FL case is smaller than that in the NF case when the precipitation systems are in the decaying stages.

Table 3 shows the average precipitation intensities in the analysis domains at the time of maximum precipitation intensity in the FL case in each sensitivity experiment. The mean precipitation intensities are for 20, 9, and 10 hours for T, B, and S cases, respectively. In T case, the mean precipitation intensity in T-FL is $2.65 \%$ larger in the convective area and $0.98 \%$ smaller in the stratiform area than that in T-NF. In B case, the mean precipitation intensity in the convective area in $\mathrm{B}-\mathrm{FL}$ is $4.38 \%$ larger than that in B-NF. The mean precipitation 

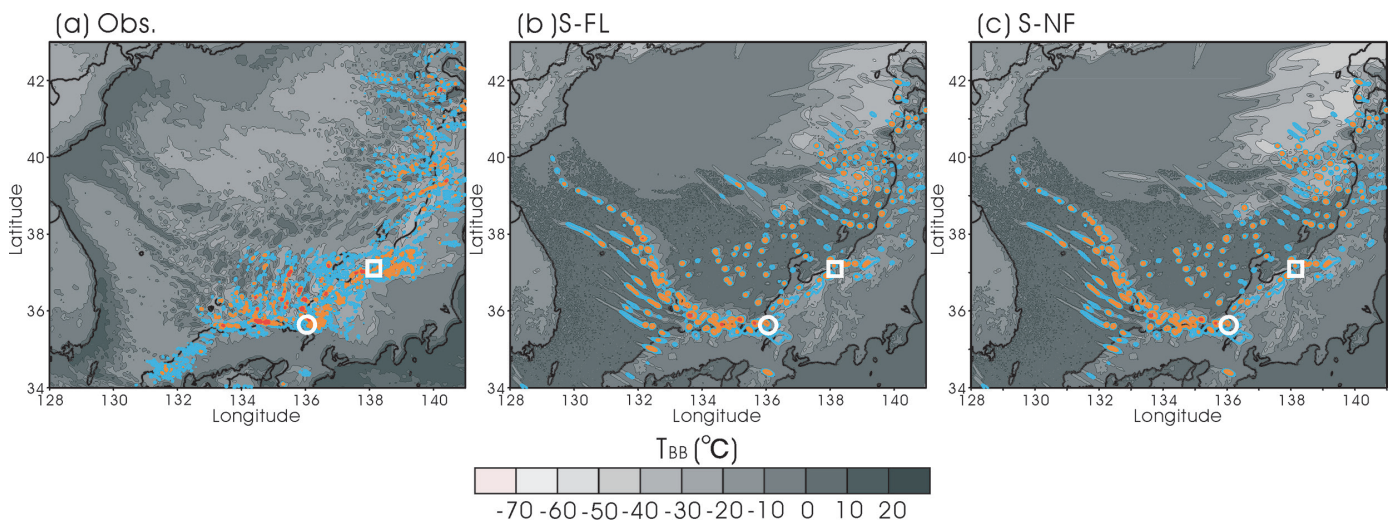

$-70-60-50-40-30-20-10 \quad 0 \quad 1020$

Fig. 8. Same as in Fig. 3, but for (a) MTSAT and JMA radar at 22Z 31 December, (b) S-FL at 10 hours (22Z 31 ), and (c) S-NF at 10 hours (22Z 31). Contours are rainfall intensity at 1 (blue), 4 (orange), and 16 (red) $\mathrm{mm} \mathrm{h}^{-1}$. White open circle and square are Tsuruga and Takada, respectively.

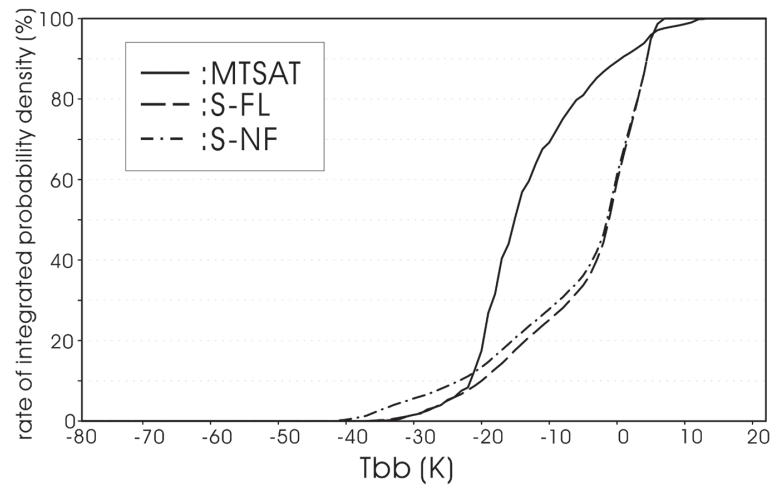

Fig. 9. Same as in Fig. 4, but for MTSAT (solid line), S-FL (dashed line), and S-NF (chain line).

intensity in the stratiform area in B-FL is $11.8 \%$ larger than that in B-NF. In $\mathrm{S}$ case, the difference between the mean precipitation intensities of S-FL and S-NF is very small. However, the mean precipitation intensity in the convective area in S-FL over the JPCZ is $1.46 \%$ larger than that in S-NF. Thus, the impact of cloud ice sedimentation is negligible for snow clouds over the Sea of Japan. Moreover, this result suggests that the cloud ice sedimentation intensifies the precipitation, especially in strong convective systems.

\section{Mechanism of precipitation intensification}

To investigate the mechanism by which cloud ice sedimentation intensifies the precipitation, the vertical distributions of the water substances and the growth processes among the water substances in the convec- tive area were analyzed for T case. In this section, we calculate the difference between the area-averaged mixing ratios of the water substances for each layer:

$$
\Delta q_{x}=q_{x}(\mathrm{~T}-\mathrm{FL})-q_{x}(\mathrm{~T}-\mathrm{NF})
$$

The vertical profiles of the differences in the water substances in the convective area at 20 hours are shown in Fig. 10. $\Delta q_{i}$ is negative (positive) above (below) a height of $10.6 \mathrm{~km}$ (Fig. 10a), which indicates that $q_{i}$ in T-FL is smaller (larger) than that in T-NF above (below) a height of $10.6 \mathrm{~km}$. These results correspond to the lower peak of $q_{i}$ shown in Fig. 5. The decrease in $q_{i}$ in the upper troposphere in T-FL is attributed to the sedimentation of cloud ice. $\Delta q_{s}$ is negative (positive) above (below) an approximate height of $8 \mathrm{~km}$ (Fig. 10b). $\Delta q_{g}$ is negative (positive) above (below) an approximate height of $6 \mathrm{~km}$. These results show that the peaks of $q_{s}$ and $q_{g}$ are lowered in T-FL. $\Delta q_{s}$ and $\Delta q_{g}$ above the $0^{\circ} \mathrm{C}$ level of $5.4 \mathrm{~km}$ in T-FL are larger than those in T-NF. $q_{s}$ and $q_{g}$ in T-FL concentrate in the thinner layer above the $0^{\circ} \mathrm{C}$ level than those in T-NF. $\Delta q_{r}$ below the $0^{\circ} \mathrm{C}$ level in T-FL is also larger than that in T-NF. These results suggest that the solid precipitation concentrated in the thin layer near the $0^{\circ} \mathrm{C}$ level melts to rain effectively. The influence of the solid precipitation on rainfall intensity is in accordance with Nomura et al. (2002). The positive $\Delta q_{i}$ below a height of $10.6 \mathrm{~km}, \Delta q_{s}$ below a height of $8 \mathrm{~km}, \Delta q_{g}$ around the $0^{\circ} \mathrm{C}$ level, and $\Delta q_{r}$ below the $0^{\circ} \mathrm{C}$ level can be attributed to the concentration of cloud ice below a height of 10.6 $\mathrm{km}$ by cloud ice sedimentation. These results indicate that cloud ice sedimentation contributes to the increase in rainfall amount at the surface. 
Table 2. Accumulated precipitation amount $(\mathrm{mm})$ averaged in the analysis domain.

\begin{tabular}{rrrrrrr}
\hline & & & \multicolumn{4}{c}{ Integrated time (h) } \\
& & & $5-10$ & $10-15$ & $15-$ & total \\
\hline \multirow{2}{*}{ T case } & \multirow{2}{*}{ con. } & FL & 20.0 & 20.3 & 21.4 & 61.7 \\
& & NF & 19.7 & 20.1 & 21.0 & 60.8 \\
& str. & FL & 5.5 & 6.3 & 5.9 & 17.7 \\
& & NF & 5.3 & 5.7 & 5.9 & 16.9 \\
\hline \multirow{2}{*}{ B case } & \multirow{2}{*}{ con. } & FL & 53.2 & 48.7 & 26.3 & 128.2 \\
& & NF & 54.9 & 45.2 & 21.9 & 122.0 \\
& \multirow{2}{*}{ str. } & FL & 18.4 & 20.8 & 5.2 & 44.4 \\
& & NF & 17.8 & 19.1 & 7.3 & 44.2 \\
\hline \multirow{2}{*}{ con. } & FL & 9.6 & 3.9 & & 13.5 \\
& & NF & 9.6 & 3.9 & & 13.5 \\
& str. & FL & 4.7 & 1.8 & & 6.5 \\
& & NF & 5.1 & 2.1 & & 7.2 \\
\hline \multirow{2}{*}{ con. } & FL & 16.9 & 8.9 & & 25.8 \\
& & NF & 16.8 & 8.9 & & 25.7 \\
& str. & FL & 7.0 & 4.1 & & 11.1 \\
& & NF & 8.0 & 4.0 & & 12.0 \\
\hline
\end{tabular}

Table 3. Precipitation rate $\left(\mathrm{mm} \mathrm{h}^{-1}\right)$ averaged in the analysis domain at 20 hours in T case, 9 hours in B case, 10 hours in $\mathrm{S}$ case.

\begin{tabular}{cccc}
\hline \multirow{2}{*}{ T case } & & FL & NF \\
& con. & 11.6 & 11.3 \\
& str. & 0.46 & 0.47 \\
\hline \multirow{2}{*}{ B case } & con. & 16.7 & 16.0 \\
& str. & 1.99 & 1.78 \\
\hline \multirow{2}{*}{ S case } & con. & 2.90 & 2.91 \\
& str. & 0.62 & 0.62 \\
\multirow{2}{*}{ JPCZ } & con. & 5.55 & 5.47 \\
& str. & 0.93 & 0.90 \\
\hline
\end{tabular}

To understand the intensification of precipitation, we focus on the growth processes of precipitation; the collection of cloud water by rain water $\left(C L_{C R}\right)$, snow $\left(C L_{C S}\right)$, and graupel $\left(C L_{C G}\right)$; and the conversion from cloud ice to snow $\left(C N_{I S}\right)$ and from snow to graupel $\left(C N_{S G}\right)$ (Fig. 1). The peaks of $C L_{C S}, C L_{C G}$, and $C N_{S G}$ are located above the $0^{\circ} \mathrm{C}$ level at 20 hours (Figs. 11a, b) because large $q_{c}$ is present around this level (Fig. 5). $C N_{I S}$ has two peaks located at heights of $6.8 \mathrm{~km}$ and $9.5 \mathrm{~km}$. The lower peak of $C N_{I S}$ is present above the peak of $C L_{C S}, C N_{S G}$, and $C L_{C G}$. The melting rate of graupel $\left(M L_{G R}\right)$ is larger than that of snow $\left(M L_{S R}\right)$
(Fig. 11c). Graupel contributes to precipitation intensity more than snow in the convective area. The larger $M L_{G R}$ indicates an increased contribution to the rainfall amount below the $0^{\circ} \mathrm{C}$ level.

We use $\Delta$ to denote the difference in the area-averaged rates of microphysical processes calculated by the subtraction of T-NF from T-FL at each layer. $\triangle C N_{I S}$ is positive (negative) below (above) a height of $9.3 \mathrm{~km}$ (Fig. 11e). $q_{i}$ is an important factor in determining $C N_{I S}$. $\Delta q_{i}$ is positive around this height (Fig. 10a). $\Delta C N_{I S}$ is positive below this level probably because of cloud ice sedimentation. $\triangle C L_{C R}, \triangle C L_{C G}$, and $\triangle C N_{S G}$ are notably positive around and below the $0^{\circ} \mathrm{C}$ level (Figs. 11d, e). In contrast, $\triangle C L_{C G}$ and $\triangle C N_{S G}$ are negative above a height of $6.2 \mathrm{~km}$. This result indicates that around the $0^{\circ} \mathrm{C}$ level, large $q_{g}$ would be efficiently formed in the thin layer by $C N_{S G}$ and the riming process $\left(C L_{C G}\right)$. The riming process is the most effective process for intensifying precipitation (Nomura and Tsuboki 2012). Positive $\Delta q_{g}$ around the $0^{\circ} \mathrm{C}$ level (Fig. 10b) causes positive $\Delta M L_{G R}$ (Fig. 11f). Positive $\Delta q_{r}$ below the $0^{\circ} \mathrm{C}$ level is caused by $M L_{G R}$ and $C L_{C R}$ (Figs. $11 \mathrm{~d}, \mathrm{f}$ ). This can be attributed to the concentration of cloud ice below a height of $10.6 \mathrm{~km}$ due to sedimentation and the effective conversion from cloud ice to solid precipitation particles. Therefore, the rainfall amount increases below the $0^{\circ} \mathrm{C}$ level.

The shape of the vertical profile of the area-averaged 

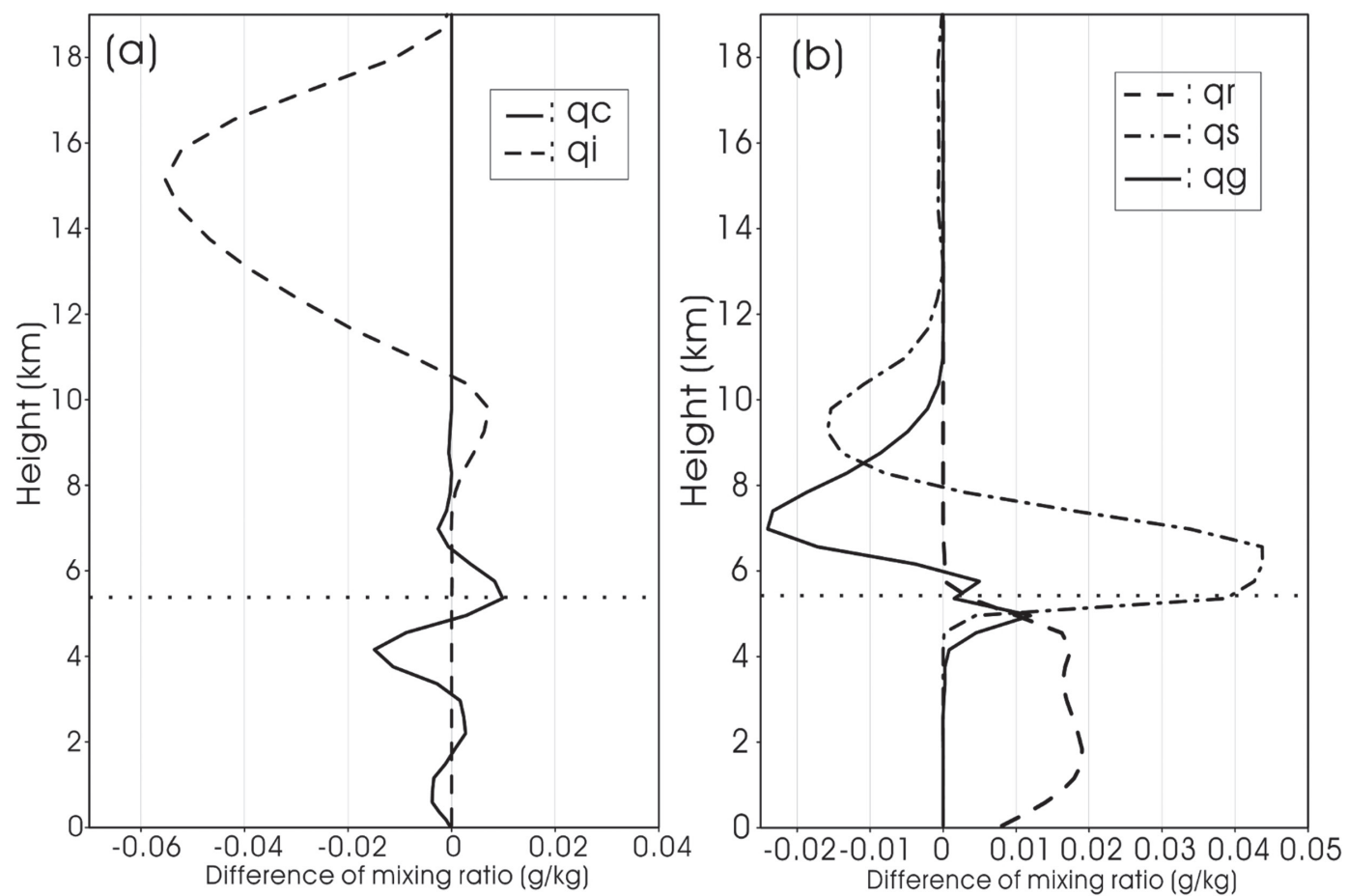

Fig. 10. Vertical profiles of the difference in mean mixing ratios obtained by subtracting T-NF from T-FL for (a) cloud and (b) precipitation in the convective area at 20 hours. (a) Difference in mean $q_{c}$ (solid line) and $q_{i}$ (dashed line). (b) Difference in $q_{r}$ (dashed line), $q_{s}$ (chain line), and $q_{g}$ (solid line). Dotted line indicates the averaged $0^{\circ} \mathrm{C}$ level in the analysis domain.

mixing ratio of water substances in the stratiform area is very similar to that in the convective area; however, $q_{c}, q_{r}$, and $q_{g}$ in the stratiform area are one-third smaller than those in the convective area (not shown). The peak of $\Delta q_{i}$ above the $0^{\circ} \mathrm{C}$ level in the stratiform area is larger than that in the convective area, although the peaks of the other water substances in the stratiform area are smaller than those in the convective area (Figs. $10,12) . \Delta q_{i}$ and $\Delta q_{s}$ are positive below a height of 11 $\mathrm{km}$ in the stratiform area. $\Delta q_{r}$, and $\Delta q_{g}$ in the stratiform area are one-third smaller than those in the convective area. The peaks of $\triangle C N_{I S}, \triangle C L_{C S}$, and $\triangle M L_{S R}$ in the stratiform area are larger than those in the convective area, although the peaks of other cloud microphysical processes in the stratiform area are smaller than those in the convective area (Figs. 11, 13). In the stratiform area, the sedimentation of cloud ice could contribute to the production of snow. Moreover, the snow contribution in this area is larger than that in the convective area relative to the intensification of precipitation.

\section{Discussion}

By introducing the simplified cloud ice fall velocity of $0.1 \mathrm{~m} \mathrm{~s}^{-1}$, the horizontal distribution and frequency of $T_{b b}$ in three FL cases showed an improvement over those in the NF cases. In B and S cases, although the cloud-top height above the strong rainfall region improved, that of frequency of low-level clouds in FL and NF was smaller than that in the MTSAT observations because the square of cloud area in both experiments was narrow in comparison with that in the observations. On the other hand, both these estimates were clearly improved in $\mathrm{T}$ case. Comparing the fall velocity of cloud ice with the averaged updraft velocity in the stratiform area, the averaged updraft velocity is below $0.1 \mathrm{~m} \mathrm{~s}^{-1}$ along most of the height range (Fig. 14). In the convective area, the averaged updraft velocity is smaller than $0.1 \mathrm{~m} \mathrm{~s}^{-1}$ above an approximately height of $9.0 \mathrm{~km}$. However, the frequency of upper-level clouds ( $T_{b b}$ is less than $-60^{\circ} \mathrm{C}$ ) in T-FL was significantly larger than that of the GMS observation (Fig. $4)$. The frequency of mid-level clouds ( $T_{b b}$ is between 

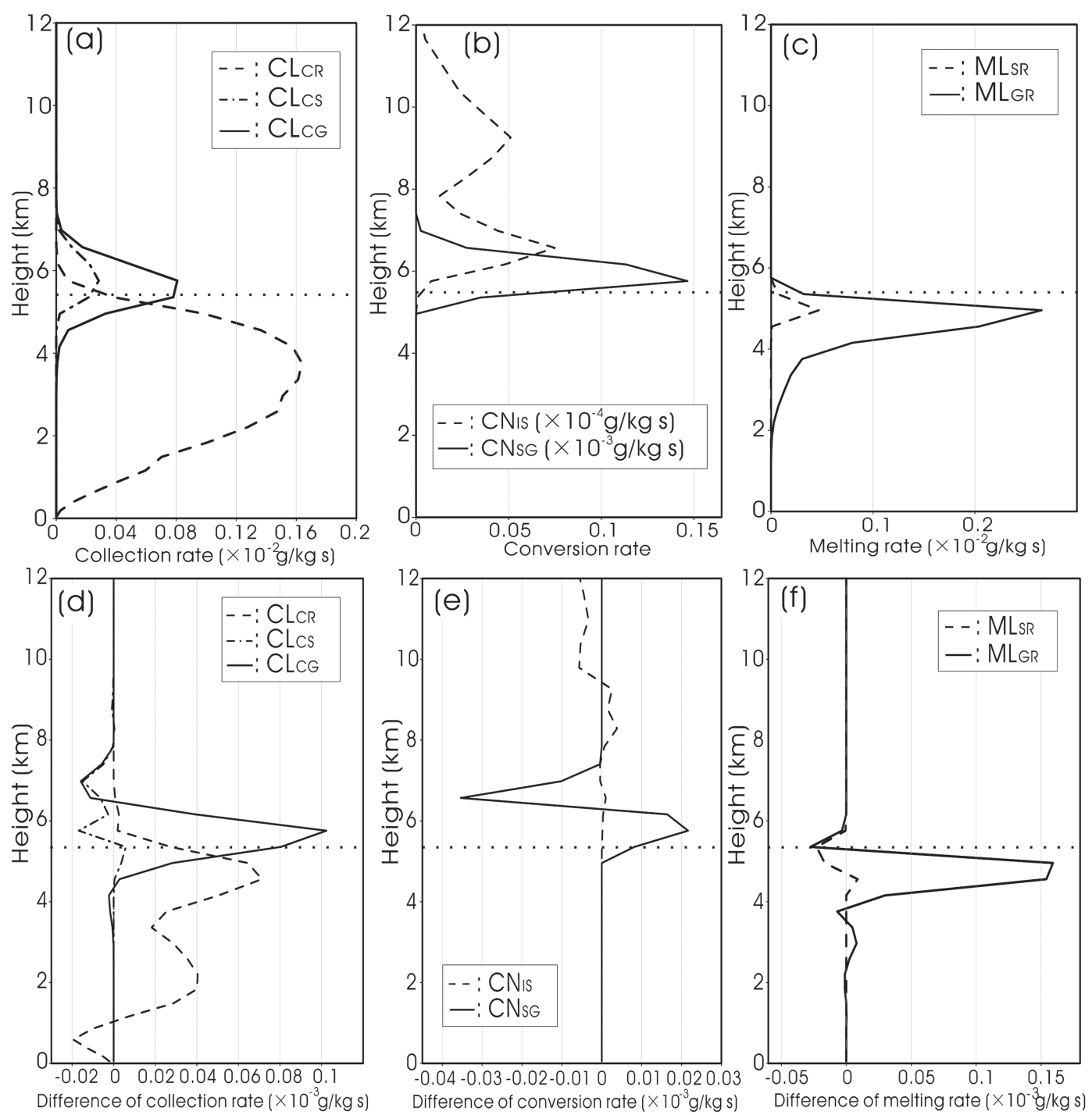

Fig. 11. Vertical profiles of mean rates of (a) collection, (b) conversion, and (c) melting in the convective area in T-FL at 20 hours. Vertical profiles of difference in mean rates are obtained by subtracting T-NF from T-FL for (d) collection, (e) conversion, and (f) melting in the convective area. In (a) and (d), $C L_{C R}$ (dashed line), $C L_{C S}$ (chain line), and $C L_{C G}$ (solid line) are shown. In (b) and (e), $C N_{I S}$ (dashed line) and $C N_{S G}$ (solid line) are shown. In (c) and (f), $M L_{S R}$ (dashed line) and $M L_{G R}$ (solid line) are shown. Dotted line indicates the averaged $0^{\circ} \mathrm{C}$ level in the analysis domain.

$-45^{\circ} \mathrm{C}$ and $-10^{\circ} \mathrm{C}$ ) in $\mathrm{T}-\mathrm{FL}$ was smaller than that of the GMS observation. This suggests that the amount of cloud ice above a height of $-60^{\circ} \mathrm{C}$ did not decrease sufficiently for lower fall velocity to become effective.

The precipitation intensity and distribution in $\mathrm{B}$ and $\mathrm{S}$ case were insufficiently represented in comparison with the radar observation. The rainfall region was adequately represented in the simulation apart from that observed at rainfall region $\mathrm{X}$ in Fig. 6a. In B-
FL, only a narrow rainfall region ( $\mathrm{Y}$ in Fig. 6b) was represented. This result suggests that the cloud ice fall velocity of $0.1 \mathrm{~m} \mathrm{~s}^{-1}$ is small for the realistic rainfall intensity and distribution. Actually, the introduced fall velocity of cloud ice is smaller than that suggested in previous studies (e.g., Heymsfield et al. 2007b; Ferrier et al. 1995). For a realistic reproduction of the cloud-top height, rainfall intensity, and rainfall distribution, it is necessary to investigate a suitable sedi- 

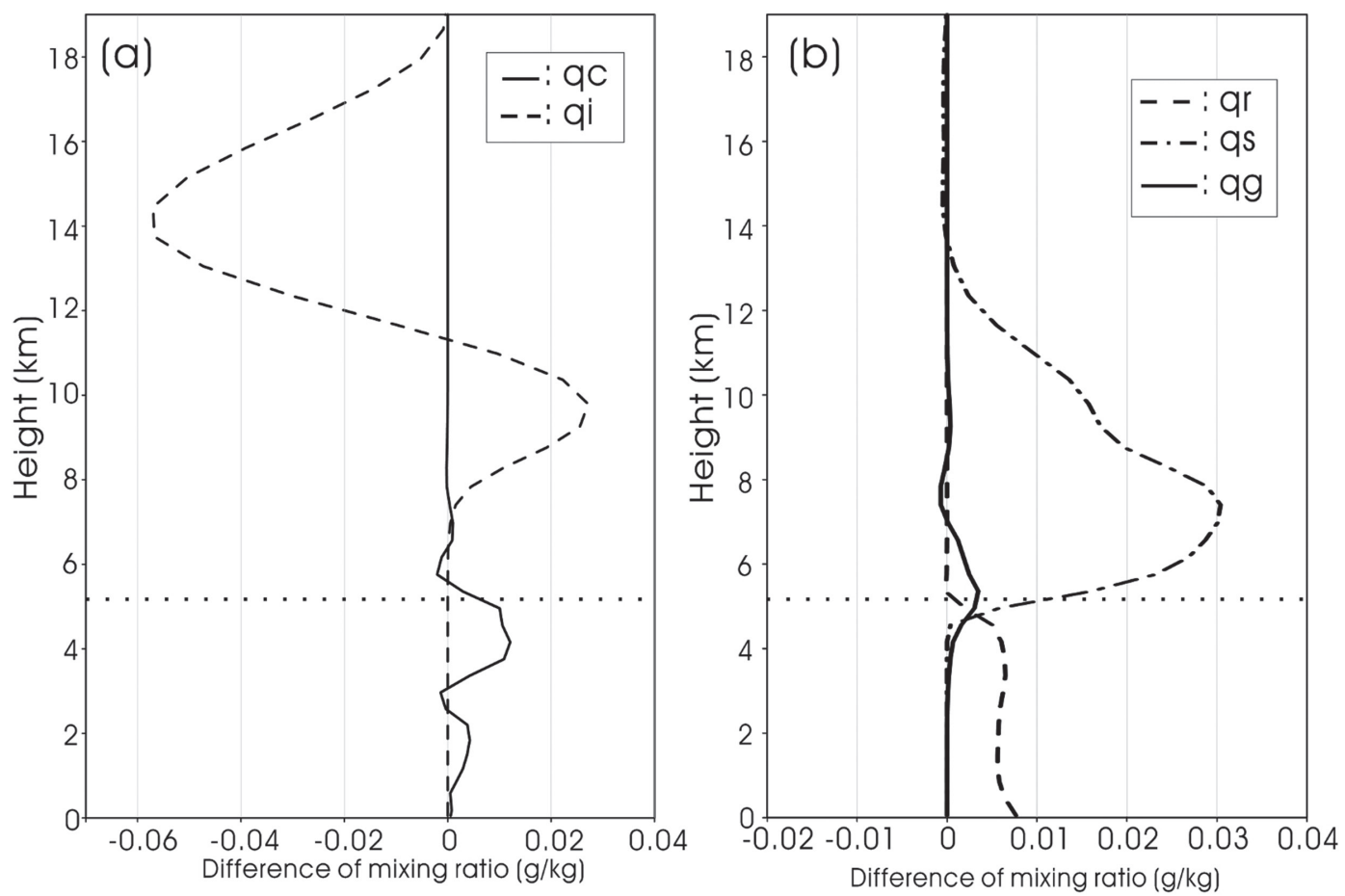

Fig. 12. Same as in Fig. 10, but for the stratiform area.
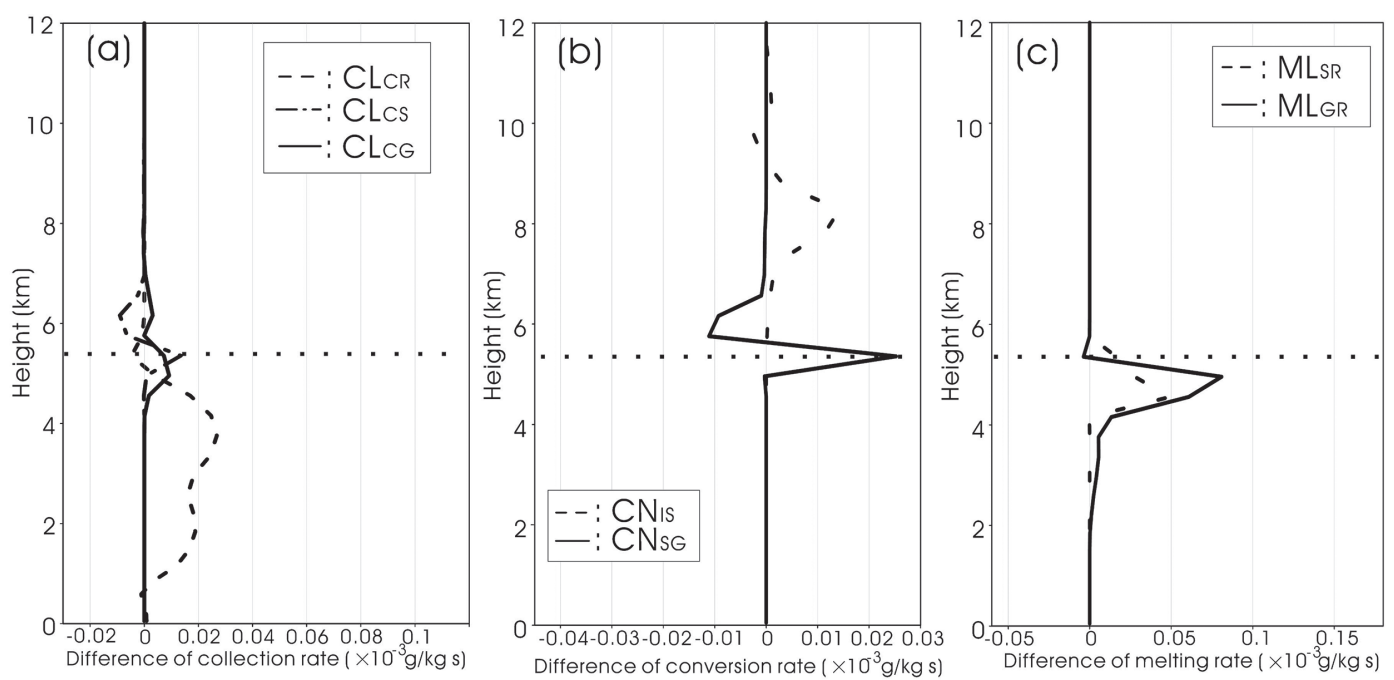

Fig. 13. Same as in Fig. 11, but for vertical profiles of the difference in mean rates obtained by subtracting T-NF from $\mathrm{T}-\mathrm{FL}$ in the stratiform area. 


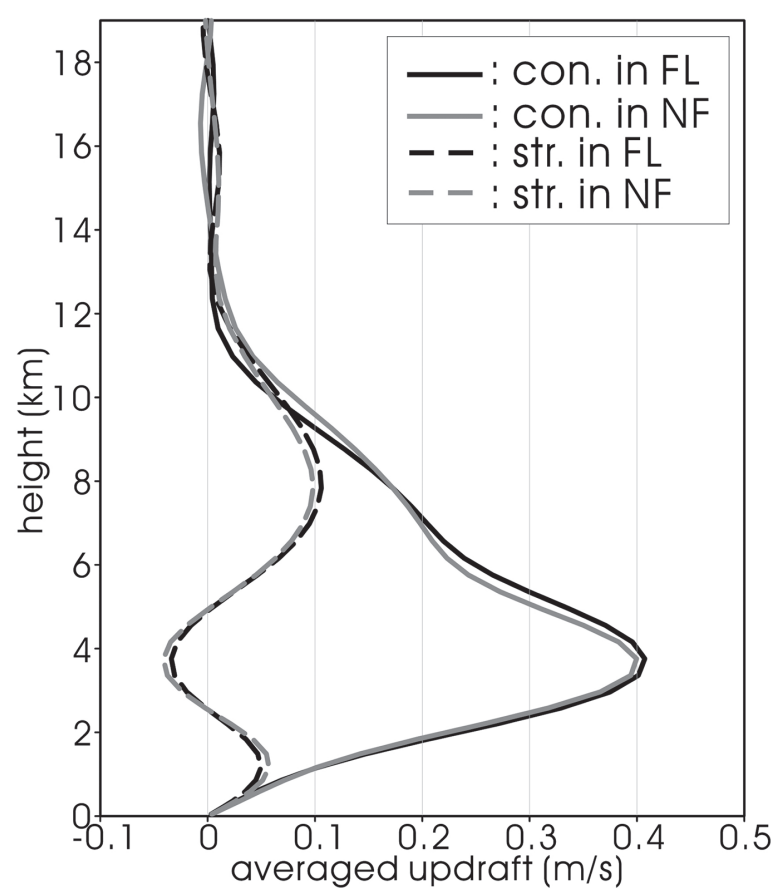

Fig. 14. Vertical profile of averaged updraft in $\mathrm{T}$ case. Black lines indicate T-FL in the convective area (solid) and the stratiform area (dashed). Gray lines indicate T-NF in the convective area (solid) and the stratiform area (dashed).

mentation process of cloud ice on the basis of its PSDs.

By introducing the sedimentation of cloud ice, the area-averaged precipitation amounts increased in the convective area in $\mathrm{T}$ and $\mathrm{B}$. The area-averaged precipitation intensified by several percent at 20 hours in $\mathrm{T}$ case, at 9 hours in B case, and at 10 hours over JPCZ in $\mathrm{S}$ case. However, in $\mathrm{S}$ case, the change in precipitation intensity was slight. Over the Sea of Japan, snow clouds are formed by shallow convection; however, the JPCZ is formed by deep convective clouds. Thus, the sedimentation of cloud ice has a large effect on intensifying the precipitation in deep convective clouds. In the FL cases, the increase in precipitation amounts and precipitation rates should be caused by the sedimentation of cloud ice. A large amount of cloud ice is consumed by the growth of solid precipitation particles. In B case and JPCZ in S case, the vertical profile of the growth process of precipitation was similar to that in $\mathrm{T}$ case (not shown). The intensification of precipitation in $\mathrm{B}$ case and JPCZ in S case probably occurred owing to the same mechanism as for $\mathrm{T}$ case.

Cloud ice accumulates by sedimentation in the upper troposphere, e.g., below a height of $9.3 \mathrm{~km}$ in T-FL.
The averaged updraft velocity is lower than $0.1 \mathrm{~m} \mathrm{~s}^{-1}$ above an approximately height of $9.0 \mathrm{~km}$ (Fig. 14) and $\Delta q_{i}$ is positive around this level (Fig. 10). Cloud ice transported by updraft or having fallen from the upperlevel would concentrate around this level. This concentration of cloud ice would convert to snow by $C N_{I S}$. When the height at which cloud ice is concentration is lowered, snow is produced in the lower height. In the convective area, cloud water would be continuously provided from the lower troposphere by updraft. Large production of cloud water in the convective area contributes to $C N_{S G}$, which depends on $C L_{C S}$. Moreover, large amount of cloud water contributes to $C L_{C G}$ (riming process) in the convective area. As a result, a large amount of graupel is produced and grown in the convective area in the FL case. The precipitation amount in the convective area in the FL case effectively increases because the collision of cloud water by graupel occurs more effectively than that by snow. The fall velocity is one of the factors that determine the collision rate. Introducing the sedimentation of cloud ice, the growth from cloud ice to precipitation particles occurs effectively in the thinner layer.

The sedimentation of cloud ice should contribute to the production of snow in the stratiform area in $\mathrm{T}$ case (Fig. 13). However, $C N_{S G}$ in the stratiform area is not effective because of the lack of riming process; the presence of cloud water is necessary for this process. As shown in Tables 2 and 3, the intensification of precipitation is not significant in the stratiform area. In $\mathrm{S}$ case, precipitation amount decreased when the sedimentation of cloud ice was introduced. The amount of snow transported from the convective area should decrease in the FL case because snow in the clouds formed by the shallow convection grows effectively and falls on the surface in the convective area. This should be attributed to the fact that snow is formed in this area. The slow fall velocity of snow should not impact the increase in rainfall amount at the surface.

\section{Summary}

This study showed that cloud ice sedimentation has an impact on cloud-top height and rainfall amount for typical precipitation systems in East Asia, including a typhoon, snow clouds over the Sea of Japan, and the Baiu front using the cloud-resolving model. The fall velocity of cloud ice was assumed to be $0.1 \mathrm{~m} \mathrm{~s}^{-1}$. The cloud-top height with the sedimentation of cloud ice was clearly lower than that without the sedimentation of cloud ice. The sedimentation of cloud ice improved the horizontal distribution and the frequency of the cloud-top height. 
The sedimentation of cloud ice in the model was effective on the intensifying precipitation by several percent in the deep convective systems, which included $\mathrm{T}$ and $\mathrm{B}$ cases, and JPCZ in S case. The sedimentation process of cloud ice had an insignificant impact on the precipitation of the snow clouds over the Sea of Japan. This result suggests that the sedimentation of cloud ice mostly impacted on active convective clouds. The cloud ice was concentrated below a height of $10 \mathrm{~km}$ by the sedimentation process and converted to snow and graupel by the microphysical growth processes. Solid precipitation was concentrated around the $0^{\circ} \mathrm{C}$ level. Therefore, the growth processes of the solid precipitation, particularly graupel in the convective area, effectively contributed to precipitation intensification below the $0^{\circ} \mathrm{C}$ level.

\section{Acknowledgments}

The authors would like to express our special thanks to Professor H. Uyeda and Mr. M. Kato of Hydrospheric Atmospheric Research Center (HyARC), Nagoya University, and Dr. Y. Shusse of National Research Institute for Earth Science and Disaster Prevention for their valuable suggestions. We thank Dr. H. Masunaga of HyARC, Nagoya University for his support in the SDSU simulations. We appreciate the helpful comments from two anonymous reviewers which helped us to improve the original manuscript. We are also grateful to the Meteorological Research Institute for providing JMA-RSM data. Numerical calculations were performed using HITACHI SR-11000 at University of Tokyo and HPC2500 at Nagoya University. Figures were drawn using the Grid Analysis and Display System (GrADS).

\section{Appendix}

\section{List of cloud microphysical processes.}

\begin{tabular}{|c|c|c|}
\hline $\begin{array}{l}\text { Notation } \\
\text { AGN }_{\text {S }}\end{array}$ & Description & $\begin{array}{l}\text { Unit } \\
k g k g^{-1} s^{-1}\end{array}$ \\
\hline $\begin{array}{l}\mathrm{AGN}_{\mathrm{I}} \\
\mathrm{AGN}_{\mathrm{S}}\end{array}$ & $\begin{array}{l}\text { decrease in number concentration of cloud ice by aggregation } \\
\text { decrease in number concentration of snow by aggregation }\end{array}$ & $\begin{array}{l}\mathrm{kg} \mathrm{kg}^{-1} \mathrm{~s}^{-1} \\
\mathrm{~kg} \mathrm{~kg}^{-1} \mathrm{~s}^{-1}\end{array}$ \\
\hline $\begin{array}{l}\mathrm{AGN}_{\mathrm{S}} \\
\mathrm{CL}_{\mathrm{CG}}\end{array}$ & $\begin{array}{l}\text { decrease in number concentration or snow by aggregation } \\
\text { collection of cloud water by graupel }\end{array}$ & $\mathrm{kg} \mathrm{kg}^{-1} \mathrm{~s}^{-1}$ \\
\hline $\mathrm{CL}_{\mathrm{CR}}$ & collection of cloud water by rain & $\mathrm{kg} \mathrm{kg}^{-1} \mathrm{~s}^{-1}$ \\
\hline $\mathrm{CL}_{\mathrm{CS}}$ & collection of cloud water by snow & $\mathrm{kg} \mathrm{kg}^{-1} \mathrm{~s}^{-1}$ \\
\hline $\mathrm{CL}_{\mathrm{IG}}$ & collection of cloud ice by graupel & $\mathrm{kg} \mathrm{kg}^{-1} \mathrm{~s}^{-1}$ \\
\hline $\mathrm{CL}_{\mathrm{IR}}$ & collection of cloud ice by rain & $\mathrm{kg} \mathrm{kg}^{-1} \mathrm{~s}^{-1}$ \\
\hline $\mathrm{CL}_{\mathrm{IS}}$ & collection of cloud ice by snow & $\mathrm{kg} \mathrm{kg}^{-1} \mathrm{~s}^{-1}$ \\
\hline $\mathrm{CL}_{\mathrm{RI}}$ & collection of rain by cloud ice & $\mathrm{kg} \mathrm{kg}^{-1} \mathrm{~s}^{-1}$ \\
\hline $\mathrm{CL}_{\mathrm{RS}}$ & collection of rain by snow & $\mathrm{kg} \mathrm{kg}^{-1} \mathrm{~s}^{-1}$ \\
\hline $\mathrm{CL}_{\mathrm{RG}}$ & collection of rain by graupel & $\mathrm{kg} \mathrm{kg}^{-1} \mathrm{~s}^{-1}$ \\
\hline $\mathrm{CL}_{\mathrm{SG}}$ & collection of snow by graupel & $\mathrm{kg} \mathrm{kg}^{-1} \mathrm{~s}^{-1}$ \\
\hline $\mathrm{CL}_{\mathrm{SR}}$ & collection of snow by rain & $\mathrm{kg} \mathrm{kg}^{-1} \mathrm{~s}^{-1}$ \\
\hline $\mathrm{CL}^{\mathrm{N}}{ }_{\mathrm{RI}}$ & collection of cloud ice number concentration by rain & $\mathrm{kg} \mathrm{kg}^{-1} \mathrm{~s}^{-1}$ \\
\hline $\mathrm{CL}^{\mathrm{N}}{ }_{\mathrm{RS}}$ & collection of snow number concentration by rain & $\mathrm{kg} \mathrm{kg}^{-1} \mathrm{~s}^{-1}$ \\
\hline $\mathrm{CN}_{\mathrm{CR}}$ & autoconversion from cloud water to rain & $\mathrm{kg} \mathrm{kg}^{-1} \mathrm{~s}^{-1}$ \\
\hline $\mathrm{CN}^{\mathrm{IS}}$ & autoconversion from cloud ice to snow & $\mathrm{kg} \mathrm{kg}^{-1} \mathrm{~s}^{-1}$ \\
\hline $\mathrm{CN}_{\mathrm{SG}}$ & autoconversion from snow to graupel & $\mathrm{kg} \mathrm{kg}^{-1} \mathrm{~s}^{-1}$ \\
\hline $\mathrm{CN}_{\mathrm{SG}}^{\mathrm{N}}$ & autoconversion from snow to graupel for number concentration & $\mathrm{kg} \mathrm{kg}^{-1} \mathrm{~s}^{-1}$ \\
\hline Fall. $q_{g}$ & fallout of graupel & $\mathrm{kg} \mathrm{kg}^{-1} \mathrm{~s}^{-1}$ \\
\hline Fall. $q_{i}$ & fallout of cloud ice & $\mathrm{kg} \mathrm{kg}^{-1} \mathrm{~s}^{-1}$ \\
\hline Fall. $q_{r}$ & fallout of rain & $\mathrm{kg} \mathrm{kg}^{-1} \mathrm{~s}^{-1}$ \\
\hline Fall. $q_{s}$ & fallout of snow & $\mathrm{kg} \mathrm{kg}^{-1} \mathrm{~s}^{-1}$ \\
\hline Fall. $\left(N_{g} / \rho\right)$ & fallout of graupel number concentration & $\mathrm{s}^{-1}$ \\
\hline Fall. $\left(N_{i} / \rho\right)$ & fallout of cloud ice number concentration & $\mathrm{s}^{-1}$ \\
\hline Fall. $\left(N_{S} / \rho\right)$ & fallout of snow number concentration & $\mathrm{s}^{-1}$ \\
\hline $\mathrm{FR}_{\mathrm{RG}}$ & freezing from rain to graupel & $\mathrm{kg} \mathrm{kg}^{-1} \mathrm{~s}^{-1}$ \\
\hline $\mathrm{FR}^{\mathrm{N}_{\mathrm{RG}}}$ & freezing from rain to graupel for number concentration & $\mathrm{kg} \mathrm{kg}^{-1} \mathrm{~s}^{-1}$ \\
\hline $\mathrm{ML}_{\mathrm{IC}}$ & melting from cloud ice to cloud water & $\mathrm{kg} \mathrm{kg}^{-1} \mathrm{~s}^{-1}$ \\
\hline $\mathrm{ML}_{\mathrm{GR}}$ & melting from graupel to rain & $\mathrm{kg} \mathrm{kg}^{-1} \mathrm{~s}^{-1}$ \\
\hline$M L_{S R}$ & melting from snow to rain & $\mathrm{kg} \mathrm{kg}^{-1} \mathrm{~s}^{-1}$ \\
\hline
\end{tabular}




$\begin{array}{ll}\text { Notation } & \text { Description } \\ \mathrm{NUA}_{\mathrm{VI}} & \text { deposition/sorption nucleation to form cloud ice } \\ \mathrm{NUC}_{\mathrm{CI}} & \text { contant freezing of cloud water to form cloud ice } \\ \mathrm{NUF}_{\mathrm{CI}} & \text { condensation freezing of cloud water to form cloud ice } \\ \mathrm{NUH}_{\mathrm{CI}} & \text { spontaneous-freezing of cloud water to form cloud ice } \\ \mathrm{PG}_{\mathrm{G}} & \text { growth of graupel with collisional collection } \\ \mathrm{SH}_{\mathrm{GR}} & \text { water shedding from graupel to form rain } \\ \mathrm{SH}_{\mathrm{SR}} & \text { water shedding from snow to form rain } \\ \mathrm{SP}_{\mathrm{GI}} & \text { secondary nucleation of cloud ice by growth of graupel } \\ \mathrm{SP}_{\mathrm{SI}} & \text { secondary nucleation of cloud ice by growth of snow } \\ \mathrm{SP}_{\mathrm{GI}} & \text { secondary nucleation of cloud ice by growth of graupel for number concentration } \\ \mathrm{SP}_{\mathrm{SI}} & \text { secondary nucleation of cloud ice by growth of snow for number concentration } \\ \mathrm{VD}_{\mathrm{VC}} & \text { vapor deposition/evaporation of cloud water } \\ \mathrm{VD}_{\mathrm{VG}} & \text { depositional growth of graupel } \\ \mathrm{VD}_{\mathrm{VI}} & \text { depositional growth of cloud ice } \\ \mathrm{VD}_{\mathrm{VR}} & \text { evaporation of rain } \\ \mathrm{VD}_{\mathrm{VS}} & \text { depositional growth of snow }\end{array}$

$$
\begin{aligned}
& \text { Unit } \\
& \mathrm{kg} \mathrm{kg}^{-1} \mathrm{~s}^{-1} \\
& \mathrm{~kg} \mathrm{~kg}^{-1} \mathrm{~s}^{-1} \\
& \mathrm{~kg} \mathrm{~kg}^{-1} \mathrm{~s}^{-1} \\
& \mathrm{~kg} \mathrm{~kg}^{-1} \mathrm{~s}^{-1} \\
& \mathrm{~kg} \mathrm{~kg}^{-1} \mathrm{~s}^{-1} \\
& \mathrm{~kg} \mathrm{~kg}^{-1} \mathrm{~s}^{-1} \\
& \mathrm{~kg} \mathrm{~kg}^{-1} \mathrm{~s}^{-1} \\
& \mathrm{~kg} \mathrm{~kg}^{-1} \mathrm{~s}^{-1} \\
& \mathrm{~kg} \mathrm{~kg}^{-1} \mathrm{~s}^{-1} \\
& \mathrm{~kg} \mathrm{~kg}^{-1} \mathrm{~s}^{-1} \\
& \mathrm{~kg} \mathrm{~kg}^{-1} \mathrm{~s}^{-1} \\
& \mathrm{~kg} \mathrm{~kg}^{-1} \mathrm{~s}^{-1} \\
& \mathrm{~kg} \mathrm{~kg}^{-1} \mathrm{~s}^{-1} \\
& \mathrm{~kg} \mathrm{~kg}^{-1} \mathrm{~s}^{-1} \\
& \mathrm{~kg} \mathrm{~kg}^{-1} \mathrm{~s}^{-1} \\
& \mathrm{~kg} \mathrm{~kg}^{-1} \mathrm{~s}^{-1}
\end{aligned}
$$

\section{References}

Asai, T., 1988: Meso-scale features of heavy snowfalls in Japan Sea coastal regions of Japan. Tenki, 35, 156-161 (in Japanese).

Black, R. A., and J. Hallett, 1986: Observations of the distribution of ice in hurricanes. J. Atmos.Sci., 43, 802-822.

Ferrier, B. S., 1994: A double-moment multiple-phase fourclass bulk ice scheme. Part I: Description. J. Atmos. Sci., 51, 249-280.

Ferrier, B. S., W. K. Tao, and J. Simpson, 1995: A doublemoment multiple-phase four-class bulk ice scheme. Part II: Simulations of convective storms in different large-scale environments and comparisons with other bulk parameterizations. J. Atmos. Sci., 52, 1001-1033.

Hayashi, S., K. Aranami, and Y. Yamada, 2008: Improvement of sedimentation process. Separate volume of annual report of NPD, 54, 98-101. (in Japanese)

Heymsfield, A. J., A. Bansemer, C. Schmitt, C. Twohy, and M. R. Poellot, 2004: Effective ice particle densities derived from aircraft data. J. Atmos. Sci., 61, 982-1003.

Heymsfield, A. J., A. Bansemer, and C. H. Twohy, 2007a: Refinements to ice particle mass dimensional and terminal velocity relationships fro ice cloud. Part I: Temperature dependence. J. Atmos. Sci., 64, 10471067.

Heymsfield, A. J., G. -J. van Zadelhoff, D. Donovan, F. Fabry, R. Hogan, and A. Illingworth, 2007b: Refinements to ice particle mass dimensional and terminal velocity relationships fro ice cloud. Part II: Evaluation and parameterizations of ensemble ice particle sedimentation velocities. J. Atmos. Sci., 64, 1068-1088.

Hong, S. -Y., J. Dudhia, and S. -H. Chen, 2004: A revised approach to ice microphysical processes for the bulk parameterization of clouds and precipitation. Mon. Wea. Rev., 132, 103-120.
Ikawa, M., and K. Saito, 1991: Description of a non-hydrostatic model developed at the forecast research department of the MRI. Technical Reports of the Meteorological Research Institute, 28, 1268-1285.

Lin, Y. -L., R. D. Farley, and H. D. Orville, 1983: Bulk parameterization of the snow field in a cloud model. $J$. Climate Appl. Meteor, 22, 1065-1092.

Liu, A. Q, G. W. K. Moore, K. Tsuboki, and I. A. Renfrew, 2004: A high-resolution simulation of convective roll clouds during a cold air out break. Geophys. Res. Lett., 31, L030101, doi:10.1029/2003GLO18530.

Masunaga, H., T. Matsui, W. K. Tao, A. Y. Hou, C. D. Kummerow, T. Nakajima, P. Bauer, W. S. Olson, M. Sekiguchi, and T. Y. Nakajima, 2010: Satellite Data Simulator Unit (SDSU): A multi-sensor, multi-spectral satellite simulator package. Bull. Amer. Meteor. Soc., 91, 1625-1632.

Matsumoto, S., K. Ninomiya, and S. Yoshizumi, 1971: Characteristic features of Baiu front associated with heavy rainfall. J. Meteor. Soc. Japan, 49, 267-281.

Milbrandt, J. A., and M. K. Yau, 2005: A multimoment bulk microphysics parameterization. Part I: Analysis of the role of the spectral shape parameter. J. Atmos. Sci., 62, 3051-3064.

Murakami, M., 1990: Numerical modeling of dynamical and microphysical evolution of an isolated cloud. -The 19 July 1981 CCOPE Cloud-. J. Meteor. Soc. Japan, 68, 107-127.

Murakami, M., and T. Matsuo, 1990: Development of the hydrometeor videosonde. J. Atmos. Oceanic Technol, 7, 613-620

Murakami, M., T. L. Clark, and W. D. Hall, 1994a: Numerical simulations of convective snow clouds over the Sea of Japan; Two-dimensional simulations of mixed layer development and convective snow cloud formation. J. Meteor. Soc. Japan, 72, 43-61. 
Murakami, M., T. Matsuo, H. Mizuno, and Y. Yamada, 1994b: Mesoscale and microscale structure of snow clouds over the Sea of Japan. Part I: Evolutions of short-lived convective snow clouds. J. Meteor. Soc. Japan, 72, 671-694.

Nomura, M., K. Tsuboki, and T. Shinoda, 2002: Effects of the cold rain processes on the formation of typhoon spiral bands. Proceeding of International Conference on Mesoscale Convective Systems and Heavy Rainfall/ Snowfall in East Asia, 240-244.

Nomura, M., and K. Tsuboki, 2012: Numerical study of precipitation intensification and ice-phase microphysical processes in typhoon spiral band. J. Meteor. Soc. Japan, 90, 685-699.

Powell, M. D., 1990: Boundary layer structure and dynamics in outer hurricane rainbands. Part I: Mesoscale rainfall and kinematic structure. Mon. Wea. Rev., 118, 891-917.

Shimizu, S., H. Uyeda, Q. Moteki, T. Maesaka, M.Takaya, K. Akaeda, T. Kato, and Y. Yoshizaki, 2008: Structure and formation mechanism of 24 May 2000 supercell-like thunderstorm observed over Kanto plain, Japan. Mon.
Wea. Rev., 136, 2389-2407.

Soong, Su-Tzai, and Y. Ogura, 1973: A comparison between axisymmetric and slab-symmetric cumulus cloud model. J. Atmos. Sci., 30, 879-893.

Steiner, M., R. House Jr., and S. E. Yuter, 1995: Climatological characterization of three-dimensional storm structure from operational radar and rain gauge data. J. Appl. Meteor., 34, 1978-2007.

Straka, J., and E. R. Mansell, 2005: A bulk microphysics parameterization with multiple ice precipitation categories. J. Appl. Meteor., 86, 1263-1274.

Tsuboki, K., and A. Sakakibara, 2002: Large-scale parallel computing of cloud resolving storm simulator. Hight Performance Computing, Springer, 243-259.

Wang, C. -C., G. T. -J. Chen, T. -C. Chen, and K. Tsuboki, 2005: A numerical study on the effects of Taiwan topography on a convective line during the Mei-Yu season. Mon. Wea. Rev., 133, 3217-3242.

Yamada, H., B. Geng, H. Uyeda, and K. Tsuboki, 2007: Thermodynamic impact of the heated landmass on the nocturnal evolution od a cloud cluster over a MeiyuBaiu front. J. Meteor. Soc. Japan, 85, 663-685. 